\title{
A multiband and wideband frequency reconfigurable slotted bowtie antenna
}

\author{
Izni Husna Idris ${ }^{1}$, Mohamad Rijal Hamid ${ }^{2}$, Kamilia Kamardin ${ }^{3}$, Mohamad Kamal A. Rahim ${ }^{4}$, \\ Huda A. Majid ${ }^{5}$ \\ ${ }^{1,2,4}$ Advanced RF \& Microwave Research Group (ARFMRG), Universiti Teknologi Malaysia, Malaysia \\ ${ }^{3}$ Department of Electronic System Engineering, University Teknologi Malaysia, Malaysia \\ ${ }^{5}$ Department of Electrical Engineering Technology, Universiti Tun Hussein Onn Malaysia, Malaysia
}

\begin{tabular}{|c|c|}
\hline Article Info & ABSTRACT \\
\hline Article history: & A multiband and wideband frequency reconfigurable antenna is presented. \\
\hline Received Feb 2, 2020 & A wideband from $3.5 \mathrm{GHz}$ to $9.0 \mathrm{GHz}$ is achieved by introducing one \\
\hline Revised Mar 22, 2020 & obtained by integrating an additional two slotted arms at the end of bowtie- \\
\hline Accepted Apr 6, 2020 & $\begin{array}{l}\text { shaped. As a result, the antenna operated at multiband mode }(1.7 \mathrm{GHz} \text { and } \\
2.6 \mathrm{GHz}) \text { and wideband mode }(3.5 \mathrm{GHz} \text { to } 9.0 \mathrm{GHz}) \text { simultaneously. }\end{array}$ \\
\hline Keywords: & $\begin{array}{l}\text { The reconfigurability of the antenna is attained through switches. Five states } \\
\text { are achieved with three pairs of switches configurations. All results are }\end{array}$ \\
\hline $\begin{array}{l}\text { Bowtie antenna } \\
\text { Multiband }\end{array}$ & $\begin{array}{l}\text { presented and discussed, including } \mathrm{S} 11 \text {, current distribution, radiation } \\
\text { pattern, and gain. The antenna is suitable to be used in multimode } \\
\text { communication systems. }\end{array}$ \\
\hline
\end{tabular}

Copyright $\odot 2020$ Institute of Advanced Engineering and Science. All rights reserved.

\section{Corresponding Author:}

Izni Husna Idris,

ARFMRG, SKE, Faculty of Engineering (FE),

Universiti Teknologi Malaysia,

Johor Bahru, Johor, Malaysia

Email: husnaidris89@gmail.com

\section{INTRODUCTION}

Advancement in modern communication systems nowadays has experienced an increase in reconfigurable antennas with frequency agility. An antenna is a core element for any wireless communication system including Global System for Mobile Communications (GSM), Wireless Local Area Network (WLAN), Worldwide Interoperability for Microwave Access (WiMAX), Long Term Evolution (LTE) and etc. However, increasing in demands for frequency bands raised an issue on a shortage of available radio frequency spectrum [1]. Also, it is quite challenging to fit multiple antennas in one small and compact systems [2]. Therefore, reconfigurable antenna is the solution to solve the spectrum usage problem. In addition, frequency reconfigurable antenna has been realized with the ability to tune or switch the operating frequency in one single antenna. Thus, the frequency reconfigurable antenna can offer a smaller communication system compare by using a conventional antenna.

Frequency reconfigurable antenna can be divided into several types such as narrowband, multiband and wideband mode of configurations. The configurations can be switched between the same mode or to another type of mode. For example, narrow-to-narrowband [3], narrow-to-wideband [4, 5], multi-tomultiband [6-10], multi-to-wideband [11-18], wide-to-wideband [19] and wide-to-narrow-to-multiband $[20,21]$ configurations have been proposed and discussed. However, in this paper, we only focus on configurations of narrow-to-wideband and multi-to-wideband.

There are two types of techniques to obtain reconfigurabily. First, by switching in and out the radiator on antenna structure. Second, by changing electrical properties of the antenna itself. Antenna 
proposed in [7, 19] used the first technique while antenna in $[16,17]$ used second technique to reconfigure their antenna's frequencies. Both of the techniques are commonly used to achieve reconfigurability. However, some of the antennas used filter to allow only certain band to operate as reported in $[4,6,18]$.

Ellipse wideband antenna with bandpass filter in [4], allows the antenna to operate in wideband mode ranging from $3.5 \mathrm{GHz}$ to $5.97 \mathrm{GHz}$. The activation of the bandpass filter produces a narrowband centered at $5.8 \mathrm{GHz}$. Antenna in [5] is able to have a narrowband mode to be passed at $4.8 \mathrm{GHz}$ and wideband mode ranging from $2.0 \mathrm{GHz}$ to $6.0 \mathrm{GHz}$.

Tapered slot antenna offers wide-to-multiband reconfiguration ability is presented in [11]. Wideband mode ranging from $1.0 \mathrm{GHz}$ to $3.8 \mathrm{GHz}$, a dual-band and triple-band modes are achieved. The dual-band and triple-band modes are operated within the wideband range. A pentagon-shaped antenna with an electromagnetic bandgap (EBG) is presented in [14]. The antenna provides dual-band mode at 1.8 $\mathrm{GHz}$ and $5.2 \mathrm{GHz}$, and a wideband mode at $1.6 \mathrm{GHz}$ to $2.37 \mathrm{GHz}$. All antennas presented in [2, 3, 8-15] have switched multi or narrowband mode within the wideband frequency range. If the multi or the narrowband mode is outside the wideband range, narrow-and-wideband modes can be operated simultaneously as shown in [22]. U-slot Fractal Koch curve microstrip antenna is able to have a narrowband mode around $1.8 \mathrm{GHz}$ to 2.0 GHz and wideband mode ranging from $2.5 \mathrm{GHz}$ to $6.8 \mathrm{GHz}$, simultaneously. By having five switches, the antenna can provide 4 states of configurations. Only one of them operates in wideband mode whereas the others operate in narrow-and-wideband mode. This type of antenna offers more functionality compared to [216] by covering wider operating bands.

Normally, a monopole antenna is used to offer a wide frequency range. However, in this paper, bowtie antenna is proposed to produce a wide range of frequency. Unlike conventional bowtie antenna in $[23,24]$, frequency range of a bowtie antenna can be increase by modifiying the antenna structure itself as proposed in [25-27]. For example, a rectangular box is inserted before the triangular bowtie-shape in [25]. The box will reduce the reflection of triangular bowtie-shape thus make the antenna has a wider bandwidth. The modification on the antenna structure gives a wide range of frequency from $5.3 \mathrm{GHz}$ to $14.2 \mathrm{GHz}$.

In this paper, a frequency reconfigurable slotted bowtie antenna is proposed. The antenna is using ideal switches to switch the operating frequency over a wide range of bands. The slotted bowtie antenna is able to operate in a wideband mode from $3.21 \mathrm{GHz}$ to $9.0 \mathrm{GHz}$, by inserting a stripline in a bowtie-shaped design. Extra features are added by providing a dual-band mode to the antenna compared to the antenna in [22]. Dual-band is realized by inserting dual-pairs of slotted arms at the end of bowtie-shaped design. Therefore, the antenna is able to achieve dual-band and wideband modes working simultaneously at a time. Moreover, the proposed antenna can have up to five different states, based on its switches configurations. The proposed antenna is suitable for multimode communication system applications.

\section{ANTENNA DESIGN}

The proposed antenna geometry is shown in Figure 1(a) with three pairs of switches to achieve frequency reconfigurability while the fabricated antenna in state one is shown in Figure 1(b). The proposed antenna consists of a slotted bowtie antenna with a stripline in the middle of bowtie-shaped and two pairs of slotted arms. the stripline is called as a rectangular box (Rectbox). The proposed antenna is implemented using an FR4 board with the height, h of $1.6 \mathrm{~mm}$, permittivity, er of 4.3 and tangent loss, tan $\delta$ of 0.002 . Stripline (Rectbox) width is $0.5 \mathrm{~mm}$ and the slotted arms width is $1.0 \mathrm{~mm}$. The width of the feed-line and the gap of the $50 \Omega$ Coplanar waveguide $(\mathrm{CPW})$ feed-line are $3.0 \mathrm{~mm}$ and $0.5 \mathrm{~mm}$, respectively.

A reference slotted bowtie antenna is shown in Figure 2, produces a dual-band mode at $3.35 \mathrm{GHz}$ and $6.92 \mathrm{GHz}$. By introducing a rectangular box as shown in Figure 3, the antenna is able to operate in wideband mode ranging from $2.73 \mathrm{GHz}$ to $9.0 \mathrm{GHz}$. Two pairs of slotted arms are added into the antenna structure to produce dual-band modes. This dual-band mode can be separated into low-band and high-band. The first arm, the longest length, operates at $1.7 \mathrm{GHz}$ known as low-band while the second arm, shortest length, operates at $2.6 \mathrm{GHz}$ known as high-band. Therefore, it enables the antenna to operate in dual-band and wideband modes simultaneously.

The switches configurations are presented in Table 1. Five states are achieved by switching on and off the switches. Switch OFF indicates that the switch is replaced with a vacuum block in the simulation process, while switch $\mathrm{ON}$ indicates that the switch is represented as a copper block. In state one, all radiators (Arm1, Arm2, bowtie and Rectbox) are functioned allowing the antenna to produce a dual-and-wideband mode. In state two, only Arm1, bowtie and Rectbox are activated, producing a single-band at low-band and wideband modes to works simultaneously. In state three, only Arm1 is decoupled while the others are activated, allowing the antenna to operate at single-band (high-band) and wideband states simultaneously. 


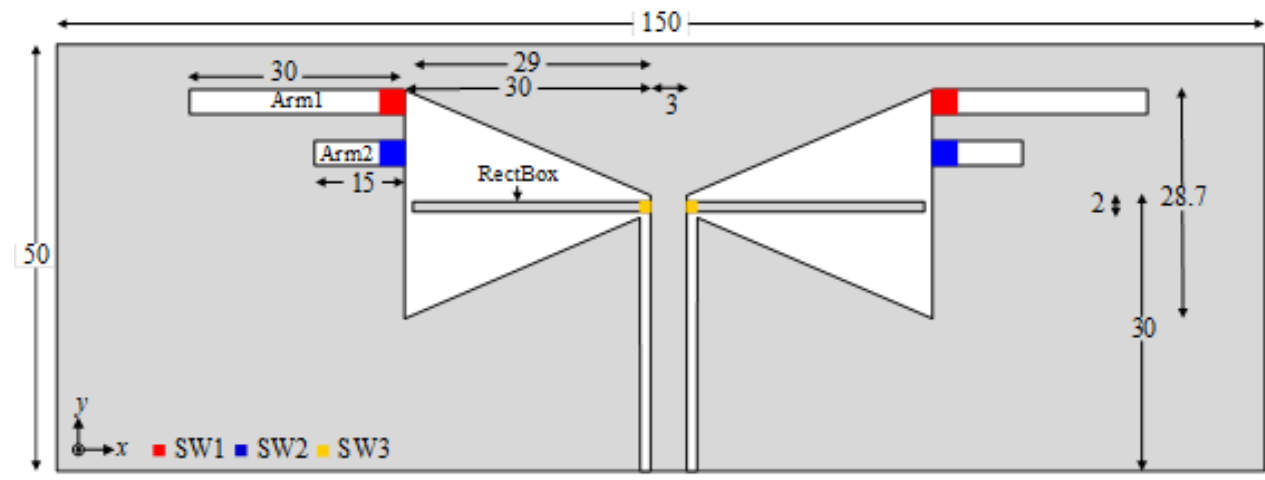

(a)

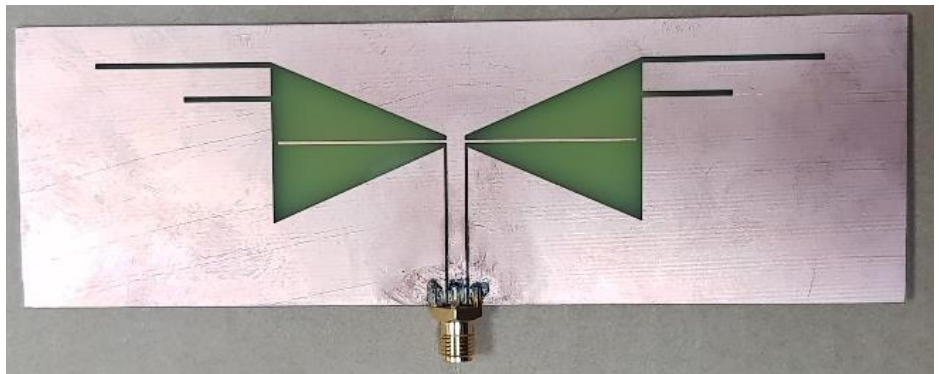

(b)

Figure 1. Antenna (a) geometry (b) fabricated antenna in state one

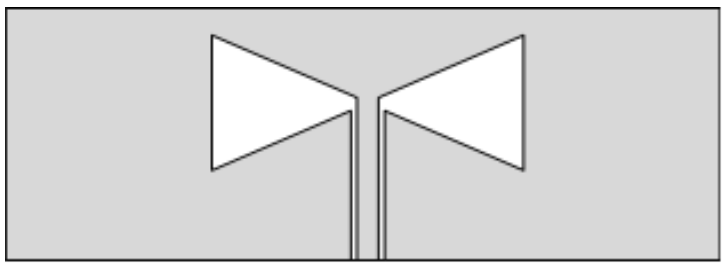

(a)

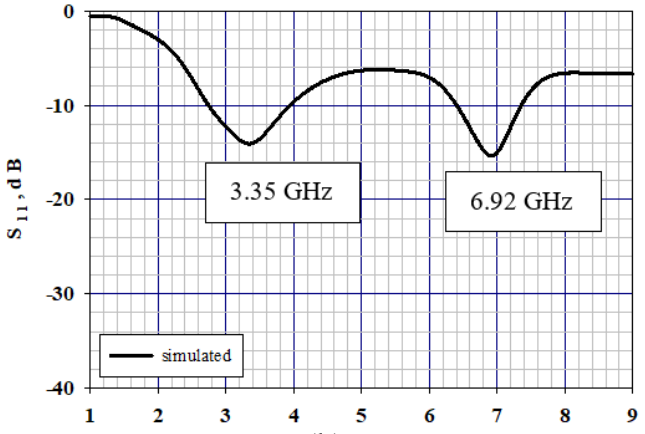

(b)

Figure 2. Reference slotted bowtie antenna (a) geometry (b) $S_{11}$

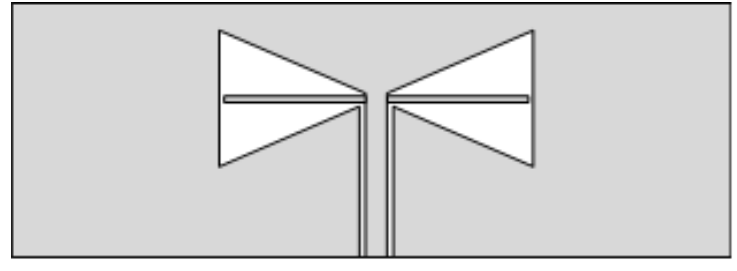

(a)

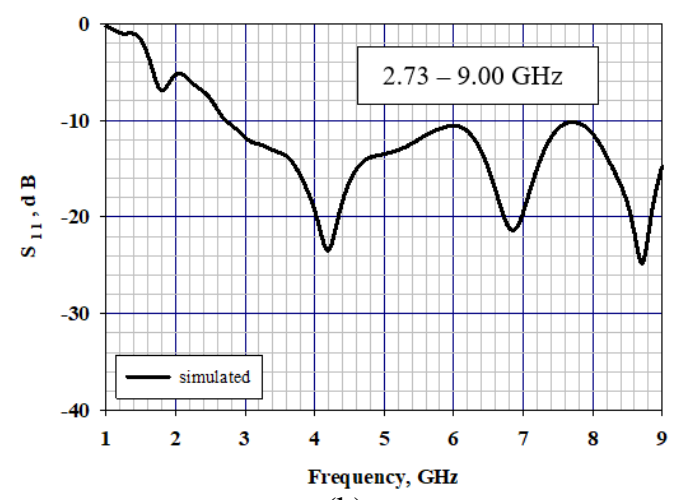

(b)

Figure 3. Reference slotted bowtie antenna with rectangular box (a) geometry (b) $S_{11}$ 
In state four, the wideband mode is obtained by decoupling Arm1 and Arm2. This can be referred to in Figure 3. Lastly, in state five, quad-band is achieved by decoupling the Rectbox. In this state, $\mathrm{S}_{11}$ results in Figure 2 can be as reference data as to how the quad-band is obtained from the antenna.

Table 1. Switches configuration

\begin{tabular}{ccccc}
\hline State & SW1 & SW2 & SW3 & Mode \\
\hline One (1) & OFF & OFF & ON & Dual-band and wideband \\
Two (2) & OFF & ON & ON & Single-band and wideband \\
Three (3) & ON & OFF & ON & Single-band and wideband \\
Four (4) & ON & ON & ON & Wideband \\
Five (5) & OFF & OFF & OFF & Quad-band \\
\hline
\end{tabular}

\section{RESULTS AND ANALYSIS}

Figure 4 shows $S_{11}$ results for all states, both simulated and measured results. For simulated results black straight line, in Figure 4(a), dual-band resonances at $1.74 \mathrm{GHz}$ and $2.63 \mathrm{GHz}$, as well as wideband states ranging from $3.21 \mathrm{GHz}$ to $9.0 \mathrm{GHz}$ is observed and operated simultaneously. Bandwidth for the dualband mode at $1.74 \mathrm{GHz}$ and $2.63 \mathrm{GHz}$ are $110 \mathrm{MHz}(1.68 \mathrm{GHz}-1.79 \mathrm{GHz})$ and $170 \mathrm{MHz}(2.57 \mathrm{GHz}-2.74$ $\mathrm{GHz}$ ), respectively. In Figure 4(b), single-band mode at $1.75 \mathrm{GHz}$ and wideband mode ranging from 2.90 $\mathrm{GHz}$ to $9.0 \mathrm{GHz}$ are achieved. Bandwidth for single-band mode at $1.75 \mathrm{GHz}$ is $110 \mathrm{MHz}(1.69 \mathrm{GHz}-1.80$ $\mathrm{GHz}$ ). In Figure 4(c), single-band and wideband configurations are obtained however, the single-band operating frequency is $2.21 \mathrm{GHz}$ and the bandwidth is $190 \mathrm{MHz}(2.11 \mathrm{GHz}-2.30 \mathrm{GHz})$ while the wideband mode is ranging from $3.11 \mathrm{GHz}$ to $9.0 \mathrm{GHz}$.

In Figure 4(d), the wideband configuration is achieved from $2.65 \mathrm{GHz}$ to $9.0 \mathrm{GHz}$. Finally, in state five, quad-band mode is achieved at $1.52 \mathrm{GHz}, 2.6 \mathrm{GHz}, 3.64 \mathrm{GHz}$ and $6.93 \mathrm{GHz}$ as in Figure 4(e). The bandwidths of the quad-bands are $80 \mathrm{MHz}(1.48 \mathrm{GHz}-1.56 \mathrm{GHz}), 410 \mathrm{MHz}(2.54 \mathrm{GHz}-2.95 \mathrm{GHz})$, $640 \mathrm{MHz}(3.39 \mathrm{GHz}-4.03 \mathrm{GHz})$ and $710 \mathrm{MHz}(6.58 \mathrm{GHz}-7.29 \mathrm{GHz})$.

Generally, the measured results agree well with the simulated results as shown in Figure 4. However, there are two major differences that we can notice. First, all lower frequency operates in $1.5 \mathrm{GHz}$ to $1.7 \mathrm{GHz}$ such as in states one, two and five, the $S_{11}$ value is lower compared to the simulated result. For example, in state one, the $S_{11}$ value for simulated at $1.7 \mathrm{GHz}$ is $-12.8 \mathrm{~dB}$ but the measured value is $-7.0 \mathrm{~dB}$ only. In state two, simulated $S_{11}$ at $1.7 \mathrm{GHz}$ is $-11.6 \mathrm{~dB}$ while the measured $S_{11}$ value is $-6.6 \mathrm{~dB}$. In state five, $-11.8 \mathrm{~dB}$ of $\mathrm{S}_{11}$ value at $1.5 \mathrm{GHz}$ is obtained in simulated value and $-7.3 \mathrm{~dB}$ is achieved in measured result. Even though the measured value is lower, the antenna still operated because more than $70 \%$ of power still transmitted [28].

Second, there is a shifting frequency in state three. In simulated, the antenna is operated from 2.11 $\mathrm{GHz}$ to $2.30 \mathrm{GHz}$. However, in the measured result, the antenna is operated from $2.2 \mathrm{GHz}$ to $2.6 \mathrm{GHz}$. Problems in the measurement value may occur due to the fabrication error or coming from the board itself. Based on the result shown in Figure 4, a filter can be introduced in order to get another mode such as singleband and dual-band only as reported in [29].

In Figure 5, current distributions for state one is shown. In Figure 5(a), current for $1.7 \mathrm{GHz}$ is mainly located around the first arm. While the current for $2.6 \mathrm{GHz}$ is located at the second arm as in Figure 5 (b). Obviously, it can be seen that arm1 and arm2 have contributed to the narrowband operation. The wideband mode current distributions are shown in Figure(c-e). Figure 5(c) shows the current distribution at $3.5 \mathrm{GHz}$. While in Figure 5(d), at $5.8 \mathrm{GHz}$ and in Figure 5(e), at 7.5 GHz. The explanation of the wideband state is mentioned in [30]. Mostly, all current distributions for all frequencies and states are the same as described for state one.

In Figure 6, radiation pattern results are presented for state one. From the figure, the H-plane pattern (black line) looks omnidirectional for all frequencies while in E-plane pattern (red line) is bi-directional type. The radiation pattern shows satisfactory performance over the entire frequency range, in all states for both simulated and measured results. Only the measured result for $\mathrm{H}$-plane is different from the simulated ones. Almost in all states, at $90^{\circ}$ and $270^{\circ}$ directions have a difference. The error is probably due to the placement of antennas during the measurement process. 


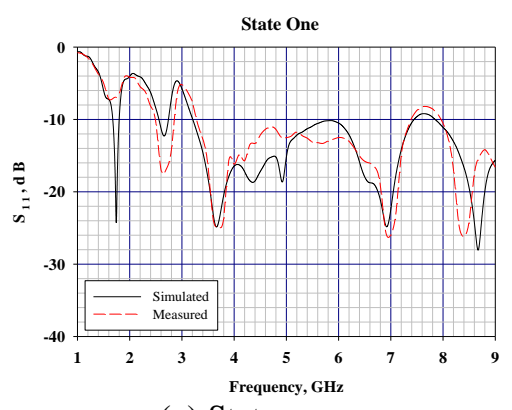

(a) State one

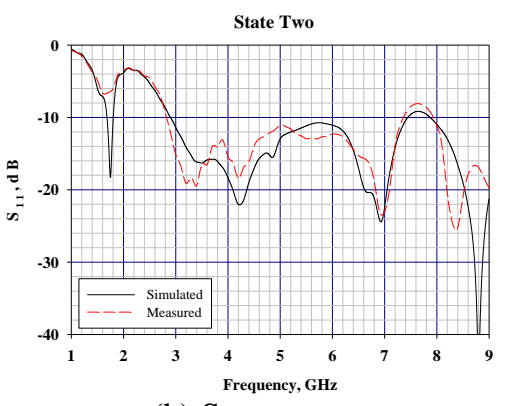

(b) State two

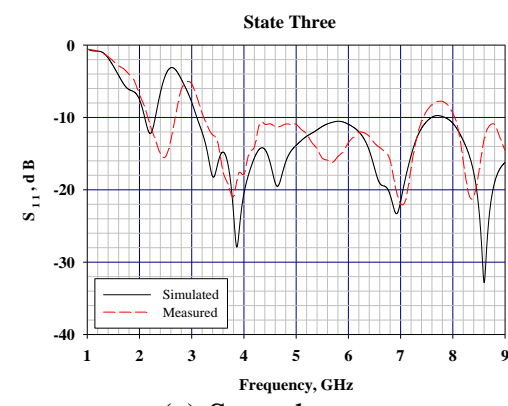

(c) State three

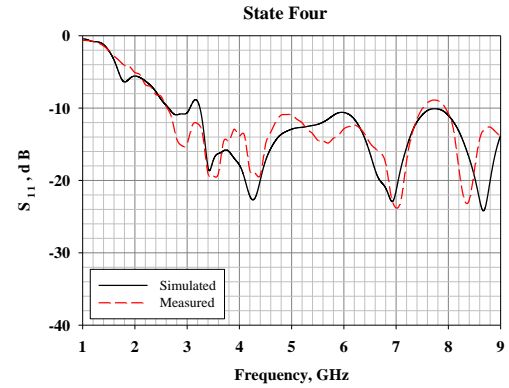

(d) State four

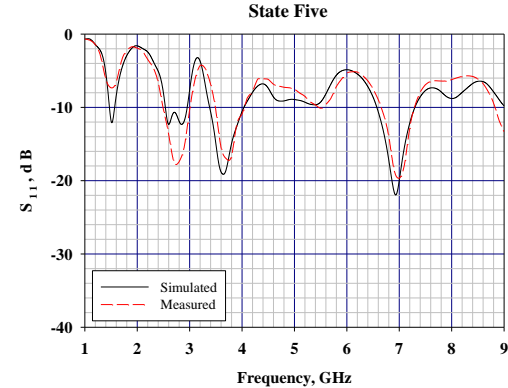

(e) State five

Figure 4. Simulated and measured $\mathrm{S}_{11}$ results

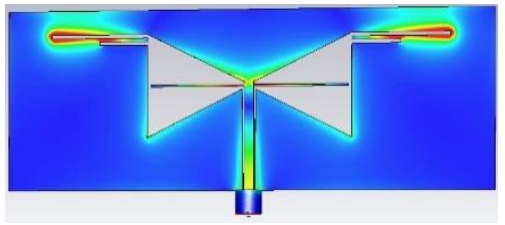

(a) $1.7 \mathrm{GHz}$

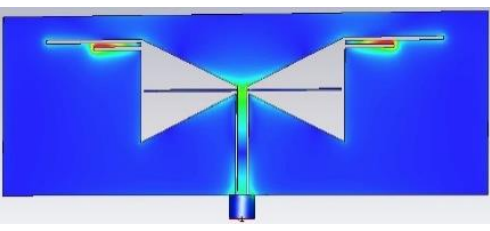

(b) $2.6 \mathrm{GHz}$

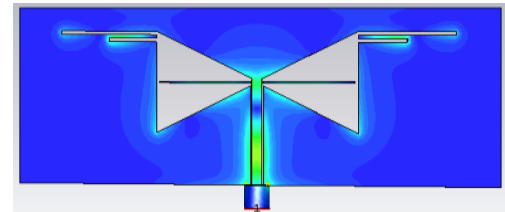

(c) $3.5 \mathrm{GHz}$

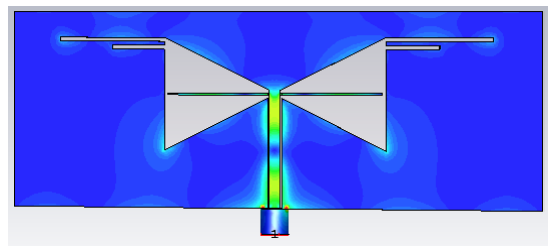

(d) $5.2 \mathrm{GHz}$

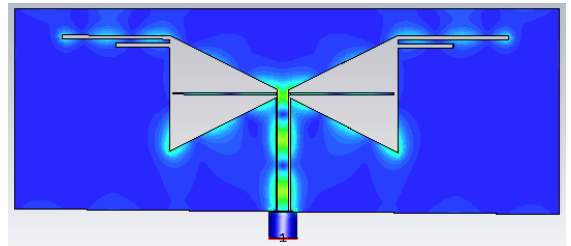

(e) $7.5 \mathrm{GHz}$

Figure 5. Simulated current distribution results

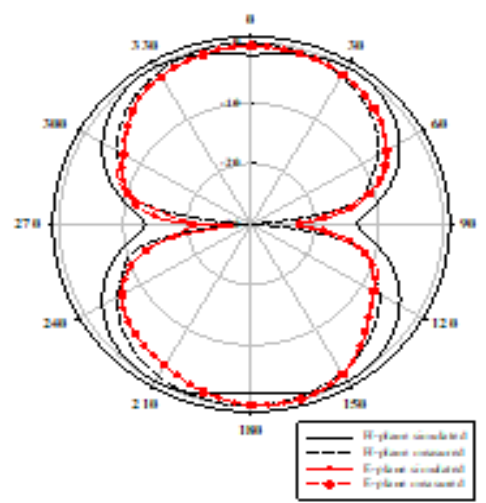

(a) $1.7 \mathrm{GHz}$

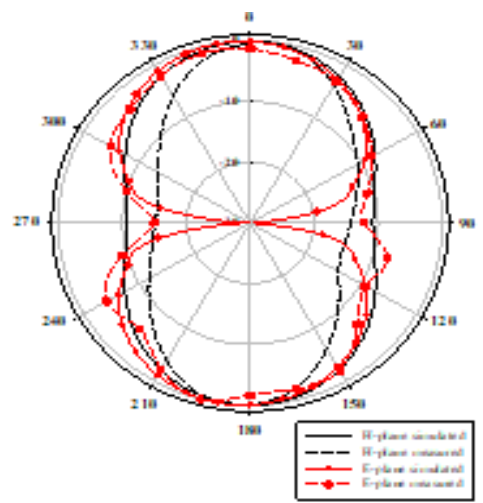

(b) $2.6 \mathrm{GHz}$

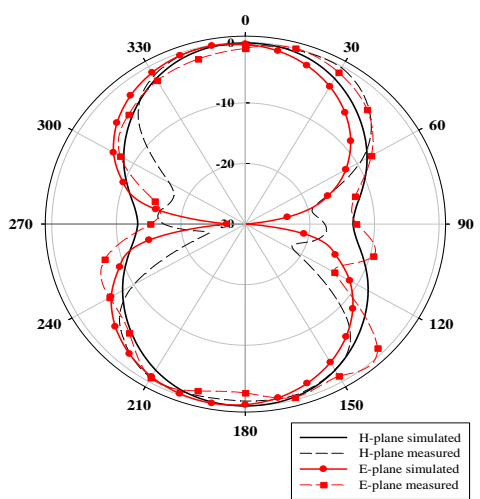

(c) $3.5 \mathrm{GHz}$ 


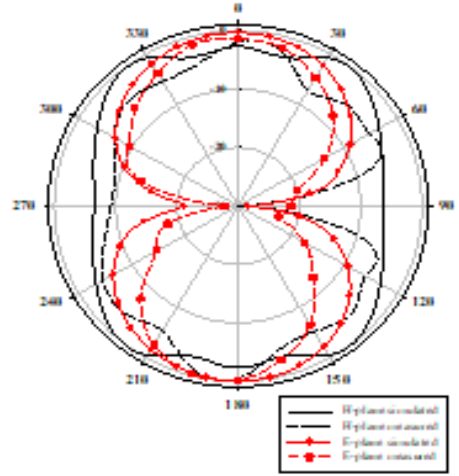

(d) $5.2 \mathrm{GHz}$

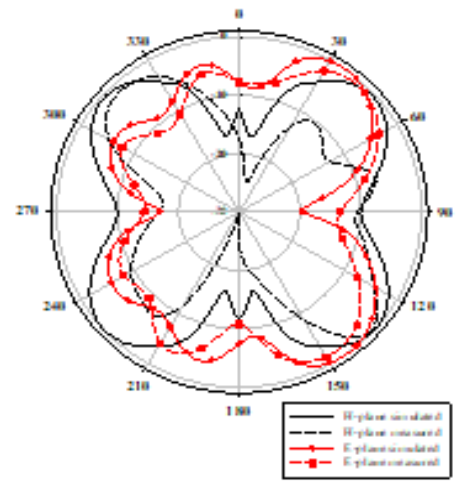

(e) $7.5 \mathrm{GHz}$

Figure 6. Simulated and measured radiation pattern results for state one (straight black line: H-plane simulated, dashed black line: H-plane measured, straight red line circle symbol: E-plane simulated, dashed red line square symbol: E-plane measured)

Table 2 tabulates the gain result for all states. Currently, only measured $\mathrm{S}_{11}$ and radiation patterns can be showed since there are no sufficient tools to measure the gain value. Simulated gain is recorded at the maximum direction in 3D-plane. The highest gain is recorded at $3.5 \mathrm{GHz}$ with a value of $6.24 \mathrm{dBi}$ while the lowest gain at $1.7 \mathrm{GHz}$ with a gain value of $0.4 \mathrm{dBi}$. As in the table, gain at lower frequency is lower compared to others. This might be due to the coupling effect or mismatch losses.

Table 2. Gain results for all states

\begin{tabular}{ccccccc}
\hline State & Mode & $\begin{array}{c}\mathrm{F} 1, \mathrm{GHz} \\
(\mathrm{Gain}, \mathrm{dBi})\end{array}$ & $\begin{array}{c}\mathrm{F} 2, \mathrm{GHz} \\
(\mathrm{Gain}, \mathrm{dBi})\end{array}$ & $\begin{array}{c}\mathrm{F} 3, \mathrm{GHz} \\
(\mathrm{Gain}, \mathrm{dBi})\end{array}$ & $\begin{array}{c}\mathrm{F} 4, \mathrm{GHz} \\
(\mathrm{Gain}, \mathrm{dBi})\end{array}$ & $\begin{array}{c}\mathrm{F} 5, \mathrm{GHz} \\
(\mathrm{Gain}, \mathrm{dBi})\end{array}$ \\
\hline One (1) & Dual-band and wideband & $1.7(0.40)$ & $2.6(4.68)$ & $3.5(5.33)$ & $5.2(5.16)$ & $7.5(2.43)$ \\
Two (2) & Single-band and wideband & $1.7(0.65)$ & - & $3.5(6.24)$ & $5.2(5.35)$ & $7.5(2.51)$ \\
Three (3) & Single-band and wideband & - & $2.2(5.25)$ & $3.5(5.62)$ & $5.2(5.24)$ & $7.5(2.72)$ \\
Four (4) & Wideband & - & - & $3.5(5.97)$ & $5.2(5.42)$ & $7.5(3.19)$ \\
Five (5) & Quad-band & $1.5(1.19)$ & $2.6(3.94)$ & $3.5(4.57)$ & - & $6.9(5.20)$ \\
\hline
\end{tabular}

\section{CONCLUSION}

The slotted bowtie antenna with additional structures provides the multi and wideband characteristics. By using the switches, the antenna has frequency reconfigurability to switch from one frequency to another. Additional features or modes can be added to the antenna by integrating the filter, to filter out unwanted frequencies. The simulated results are agreed well with the measured result in terms of $\mathrm{S}_{11}$ and radiation patterns. This antenna is suitable for future multimode wireless communication networks. The ideal switches will be replaced by real switches such as pin-diode and MEMS switches, in order to be implemented in a real environment.

\section{ACKNOWLEDGEMENTS}

The authors would like to acknowledge the Ministry of Education (MoE) Malaysia, Universiti Teknologi Malaysia (UTM) under the research grant (Vote No.: Q.J130000.3551.06G94), Universiti Tun Hussein Onn (UTHM) under the research grant (Vote No.: CRG-K034), Advanced RF and Microwave Research Group (ARFMRG) and Communication Systems and Networks (CSN) antenna laboratory for supporting this work.

\section{REFERENCES}

[1] R. M. C. Cleetus and G. J. Bala, "Frequency Reconfigurable Antennas for Cognitive Radio Applications: A Review," Int. J. Electr. Comput. Eng., vol. 9, no. 5, pp. 3542-3549, 2019.

[2] A. Romputtal and C. Phongcharoenpanich, "Frequency Reconfigurable Multiband Antenna with Embedded Biasing Network," IET Microwaves, Antennas Propag., vol. 11, no. 10, pp. 1369-1378, 2017.

[3] A. I. Al-Muttairy and M. J. Farhan, "Frequency Reconfigurable Monopole Antenna with Harmonic Suppression for IoT Applications," TELKOMNIKA (Telecommunication Comput. Electron. Control)., vol. 18, no. 1, p. 10, 2020. 
[4] M. C. Lim, M. K. A. Rahim, M. R. Hamid, A. A. Eteng, and M. F. Jamlos, "Frequency Reconfigurable Antenna for WLAN Application," Microw. Opt. Technol. Lett., vol. 59, no. 1, pp. 171-176, 2017.

[5] M. C. Lim, S. K. A. Rahim, M. R. Hamid, P. J. Soh, and A. A. Eteng, "Semi-Transparent Frequency Reconfigurable Antenna with DGS," Microw. Opt. Technol. Lett., vol. 60, no. 1, pp. 6-13, 2018.

[6] S. Kingsly et al., "Multiband Reconfigurable Filtering Monopole Antenna for Cognitive Radio Applications," IEEE Antennas Wirel. Propag. Lett., vol. 17, no. 8, pp. 1416-1420, 2018.

[7] F. Xie, X. J. Huang, and M. S. Tong, "A Novel Design of Frequency-Reconfigurable Antenna for Wireless Communication,” 2018 Prog. Electromagn. Res. Symp., pp. 1809-1812, 2018.

[8] M. J. Sathikbasha and V. Nagarajan, "DGS Based Multiband Frequency Reconfigurable Antenna for Wireless Applications,” 2019 IEEE Int. Conf. Commun. Signal Process., pp. 908-912, 2019.

[9] Y. B. Chaouche, M. Nedil, and I. Messaoudene, "A Bandwidth Reconfigurable Multiband Fractal Antenna for Wireless Applications,” 2019 IEEE Int. Symp. Antennas Propag. Usn. Radio Sci. Meet., pp. 917-918, 2019.

[10] A. A. Jabber, A. K. Jassim, and R. H. Thaher, "Compact Reconfigurable PIFA Antenna for Wireless Applications," TELKOMNIKA (Telecommunication Comput. Electron. Control)., vol. 18, no. 2, pp. 595-602, 2020.

[11] S. Chagharvand, M. R. Hamid, M. R. Kamarudin, and F. Ghanem, "Reconfigurable Multiband Tapered Slot Antenna," Microw. Opt. Technol. Lett., vol. 57, no. 9, pp. 2182-2186, 2015.

[12] M. Tewari, A. Yadav, and R. P. Yadav, "Frequency Reconfigurable Antenna: Using Pixel Ground," 2016 Int. Conf. Recent Adv. Innov. Eng. ICRAIE 2016, pp. 1-6, 2016.

[13] S. Tripathi, A. Mohan, and S. Yadav, "A Compact Frequency-Reconfigurable Fractal UWB Antenna Using Reconfigurable Ground Plane,” Microw. Opt. Technol. Lett., vol. 59, pp. 1800-1808, 2017.

[14] R. Dewan, M. K. A. Rahim, M. R. Hamid, M. F. M. Yusoff, H. A. Majid, and B. A. F. Esmail, "Dual Band to Wideband Pentagon-Shaped Patch Antenna with Frequency Reconfigurability Using EBGs," Int. J. Electr. Comput. Eng. (IJECE), vol. 8, no. 4, pp. 2557-2563, 2018.

[15] B. Belkadi, Z. Mahdjoub, M. L. Seddiki, and M. Nedil, "UWB Monopole Antenna with Reconfigurable Notch Bands based on Metamaterials Resonators," 2018 IEEE Antennas Propag. Soc. Int. Symp. Usn. Natl. Radio Sci. Meet., pp. 285-286, 2018.

[16] S. Keerthipriya, C. Saha, J. Y. Siddiqui, and Y. M. M. Antar, "Dual tunable multifunctional reconfigurable vivaldi antenna for cognitive/multi-standard radio applications," 2019 IEEE Int. Symp. Antennas Propag. Usn. Radio Sci. Meet., pp. 1833-1834, 2019.

[17] C. Borda-Fortuny, K. F. Tong, and K. Chetty, "Low-cost mechanism to reconfigure the operating frequency band of a Vivaldi antenna for cognitive radio and spectrum monitoring applications," IET Microwaves, Antennas Propag., vol. 12, no. 5, pp. 779-782, 2018.

[18] W. Xie, J. Wang, W. Wang, Y. Wu, and Y. Liu, "Wideband/Dual-band Reconfigurable Filtering Antenna for Wireless Communication Systems," 2019 IEEE MTT-S Int. Wirel. Symp., pp. 1-3, 2019.

[19] A. Bhattacharjee and S. Dwari, "Wideband Frequency Reconfigurable Patch Antenna for Various Wireless Applications," 2018 IEEE Indian Conf. Antennas Propag., pp. 1-4, 2018.

[20] A. A. Jabber and R. H. Thaher, "Compact tri-band T-shaped frequency reconfigurable antenna for cognitive radio applications," Bull. Electr. Eng. Informatics (BEEI), vol. 9, no. 1, pp. 212-220, 2020.

[21] A. A. Jabber and R. H. Thaher, "New Compact Multiband Inverted-L Frequency Reconfigurable Antenna for Cognitive Radio Applications," Indones. J. Electr. Eng. Comput. Sci. (IJEECS), vol. 9, no. 1, pp. 267-275, 2020.

[22] Y. A. Nafde and R. Pande, "Performance Analysis of Reconfigurable U-Slot Fractal Antenna for Wireless Applications," Proc. 2016 IEEE Int. Conf. Wirel. Commun. Signal Process. Networking, WiSPNET 2016, pp. 931-935, 2016.

[23] A. S. Emhemmed and K. Elgaid, "G-band bowtie dipole antenna," 2009 3rd Eur. Conf. Antennas Propag., pp. 998-1000, 2009.

[24] K. C. Pan, H. Jiang, D. Brown, C. H. Zhang, M. Patterson, and G. Subramanyam, "Frequency tuning of CPW bowtie antenna by ferroelectric BST thin film varactors," Proc. 2011 IEEE Natl. Aerosp. Electron. Conf., pp. 1-4, 2011.

[25] A. A. Eldek, A. Z. Elsherbeni, and C. E. Smith, "Wide-Band Modified Printed Bow-Tie Antenna with Single and Dual Polarization for C- and X-Band Applications," IEEE Trans. Antennas Propag., vol. 53, no. 9, pp. 3067-3072, 2005.

[26] Q. Lu, L. Zhou, C. Tan, and G. Lu, "A Novel Wide Beam UWB Antenna Design for Through-the-Wall Radar," 2010 Int. Conf. Microw. Millim. Wave Technol., vol. 5, pp. 1912-1915, 2010.

[27] S. Rashid, Y. Wu, and Y. Ding, "Monopole-Like Bowtie Slot Antenna for Ultrawideband Applications," 2016 IEEE Int. Conf. Comput. Electromagn., pp. 376-378, 2016.

[28] "VSWR Conversion Table." [Online]. Available: https://www.everythingrf.com/tech-resources/vswr. [Accessed: 28-Jan-2020].

[29] I. H. Idris, M. R. Hamid, K. Kamardin, and M. K. A. Rahim, "Wide to Multiband Elliptical Monopole Reconfigurable Antenna for Multimode Systems Applications," TELKOMNIKA (Telecommunication Comput. Electron. Control)., vol. 17, no. 4, pp. 1663-1669, 2019.

[30] J. Liang, C. C. Chiau, X. Chen, and C. G. Parini, "Study of Printed Circular Disc Monopole Antenna for UWB Systems," IEEE Trans. Antennas Propag., vol. 53, no. 11, pp. 3500-3504, 2005. 


\section{BIOGRAPHIES OF AUTHORS}
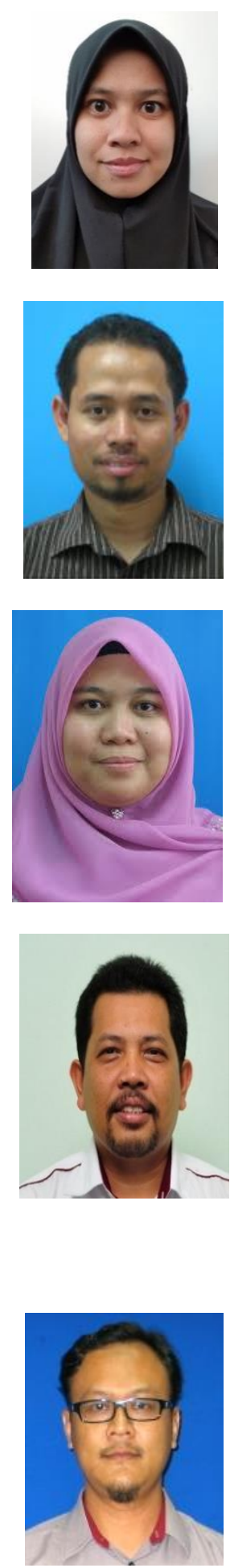

Izni Husna Idris received B. Eng. and M. Eng. degrees in Electrical Engineering from Universiti Teknologi Malaysia (UTM). Now, she is pursuing the PhD. degree in Advanced RF and Microwave Research Group (ARFMRG), UTM Johor, Malaysia. Her research interests include reconfigurable antenna design and multi-function antenna for wireless communication systems application.

Mohanmad Rijal Hamid received the M.Sc. degrees in communication engineering from the Universiti Teknologi Malaysia, Johor Bahru, Malaysia, in 2001 and the PhD Degree at the University of Birmingham, Birmingham, U.K. in 2011. He has been with Universiti Teknologi Malaysia (UTM) at the School of Electrical Engineering, Faculty of Engineering, UTM, since 1999. Currently his position is a Senior Lecturer. His major research interest is reconfigurable antenna design for multimode wireless applications.

Kamilia Kamardin received her B.Eng. Electronic (Communications) from the University of Sheffield, U.K., in 2004 and obtained her M.Sc. in Information Technology (Data Communications and Networking) from Universiti Teknologi Mara (UiTM), Malaysia in 2007. She received her Ph.D. in Electrical Engineering (Communications) from Universiti Teknologi Malaysia (UTM), Malaysia in 2014. Currently she serves as senior lecturer at Department of Electronic Systems Engineering, Malaysia-Japan International Institute of Technology (MJIIT), Universiti Teknologi Malaysia (UTM), Kuala Lumpur. Her research interests include antennas, wireless communication, wearable communication, body centric communication, metamaterials and Internet of Things (IoT).

Mohamad Kamal A. Rahim received the B Eng. degree in Electrical and Electronic Engineering from University of Strathclyde, UK, in 1987. In 1989, he joined the Department of Communication Engineering, Faculty of Electrical Engineering Universiti Teknologi Malaysia Kuala Lumpur as an Assistant Lecturer A. He obtained his M. Eng. Science from University of New South Wales Australia in 1992 and PhD degrees in Electrical Engineering from University of Birmingham UK in 2003. He is the Professor in RF and Antenna at Faculty of Electrical Engineering Universiti Teknologi Malaysia. His research interest includes the areas of design of dielectric resonator antennas, microstrip antennas, small antennas, microwave sensors, RFID antennas for readers and tags, Multifunction antennas, microwave cicuits, EBG, artificial magnetic conductors, metamaterials, phased array antennas, computer aided design for antennas and design of millimeter frequency antennas. He has published over 200 articles in journals and conference papers.

Huda A Majid received the B. Eng. degree in Electrical Engineering (Telecommunication) from Universiti Teknologi Malaysia, in 2007. He then obtained his M. Eng. in 2010 and $\mathrm{PhD}$ degrees in Electrical Engineering in 2013, at Universiti Teknologi Malaysia. He is currently a lecturer in the Department of Electrical Engineering Technology, Faculty of Engineering Technology, Universiti Tun Hussein Onn Malaysia. His research interest includes the areas of design of microstrip antennas, small antennas, reconfigurable antennas, metamaterials structure, metamaterial antennas and millimeter wave antennas. He has published over 100 articles in journals and conference papers. 